\title{
STUDI EMPIRIS RESPON PETANI SUKU DAYAK TERHADAP PENYULUHAN PERTANIAN DI ENTIKONG KALIMANTAN BARAT
}

\author{
Rifqi Pascavery Dwipani ${ }^{1}$, Maya Khairunisa ${ }^{1}$, Ameilia Zuliyanti Siregar ${ }^{2,1}$ \\ Nurliana Harahap ${ }^{1}$ \\ ${ }^{1}$ Jurusan Penyuluhan Pertanian, Politeknik Pembangunan Pertanian Medan. \\ ${ }^{2}$ Universitas Sumatera Utara \\ Email: Mayawahiid@gmail.com
}

\begin{abstract}
ABSTRAK
Komunikasi merupakan salah satu unsur penting didalam penyuluhan pertanian. Tidak bisa dipungkiri bahwa bahasa sangat berpengaruh terhadap keberhasilan sebuah komunikasi. Penelitian ini mengkaji tentang respon petani suku dayak terhadap penyuluhan pertanian dengan komunikasi formal didesa Entikong, Kabupaten Sanggau, Provinsi Kalimantan Barat. Adapun Metode yang digunakan pada pengkajian ini adalah deskriptif kualitatif, wawancara dengan kuisioner dan dokumentasi, sedangkan metode analisis data yang digunakan adalah Skala Likert dengan ketentuan total nilai yang diperoleh dalam nilai maksimum di kali 100\%. Adapun Variabel yang diuji berupa umur, jenis kelamin, pendidikan formal, dan luas lahan. Hasil penelitian menunjukkan bahwa tingkat respons petani suku dayak berdasarkan perbuahan pengetahuan sebesar $21,57 \%$, dengan presentase sebelum penyuluhan (prittest) sebesar $41,75 \%$ dan persentase sesudah penyuluhan pertanian (posttest) sebesar $63,32 \%$. Manakala faktor umur, tingkat pendidikan, jenis kelamin, dan luas lahan berpengaruh signifikan terhadap respon petani Suku Dayak terhadap penyuluhan pertanian dengan menggunakan bahasa Indonesia di Entikong, Kalimantan Barat.

Kata Kunci-Bahasa; Komunikasi; Penyuluhan Pertanian.
\end{abstract}

\section{PENDAHULUAN}

Sektor pertanian merupakan salah satu peranan penting dan strategis dalam pembangunan nasional, yaitu sebagai penyedia bahan pangan bagi penduduk yang saat ini sudah mendekati 260 juta jiwa. Di dalam kegiatan pertanian, kebutuhan penyuluhan sangat penting untuk meningkatkan hasil produksi. Didalam penyuluh pertanian, banyak kendala yang dialami oleh para penyuluh salah satu diantaranya adalah bahasa didalam berkomunikasi. Penyuluh dituntut memiliki kemampuan berkomunikasi agar materi dapat tersampaikan dengan baik. Penggunaan bahasa yang baik dan benar adalah salah satu pendukung komunikasi Penyuluhan. Bahasa yang digunakan penyuluh pada dasarnya adalah Bahasa Indonesia.

Mayoritas penduduk Indonesia masih tetap menggunakan bahasa daerah untuk komunikasi sehari-hari di rumah tangga. Menurut data statistik, sebesar 79,5\% dari seluruh populasi penduduk usia 5 tahun ke atas melakukan komunikasi sehari-hari di rumah tangga dengan menggunakan bahasa daerah, sebesar 19,9\% menggunakan bahasa Indonesia dan sebesar 0,3\% lainnya masih menggunakan bahasa asing (BPS, 2016).

Suku Dayak merupakan suku terbesar di Kalimantan Barat dengan penguasaan sumber daya lahan yang juga paling luas, serta memiliki potensi peningkatan produktifitas pertanian yang tinggi. Namun seperti yang ditegaskan oleh De Vito (1997) yang menyatakan bahwa setiap masyarakat memiliki cara tersendiri dalam berkomunikasi, termasuk dalam pola komunikasi interpersonal di dalam komunitasnya. Kebiasaan masyarakat Dayak yang selama ini masih menggunakan bahasa daerah Dayak menyebabkan terbatas kemampuannya dalam akses informasi dan inovasi teknologi khususnya bidang pertanian. Hal ini menghambat kemampuan mereka untuk meningkatkan produktifitas usahatani, pendapatan dan kesejahteraannya.

Penyuluhan pertanian dapat diartikan sebagai proses penyebarluasan informasi yang berkaitan dengan upaya perbaikan cara-cara bertani dan berusahatani demi tercapainya peningkatan produktivitas, pendapatan petani dan perbaikan kesejahteraan keluarga/masyarakat yang diupayakan melalui kegiatan pembangunan pertanian (Mardikanto, 2013). Sedangkan Komunikasi Penyuluhan Pertanian merupakan suatu pernyataan antar manusia yang berkaitan dengan kegiatan di bidang 
pertanian, baik secara perorangan maupun secara berkelompok, yang sifatnya umum dengan menggunakan lambang-lambang tertentu (Soekartawi, 1988).

Menurut data statistika, 19,15\% masyarakat Dayak Tinggal diperkotaan dan 80,85 \% lainnya tinggal diperdesaan. Sedangkan didalam penggunaan bahasa, Sebanyak 439.956 atau 11,17 \% masyarakat di Kalimantan barat menggunakan bahasa Indonesia, sebanyak 3.233.047 atau 82,19\% menggunakan bahasa daerah, dan 260.156 orang atau 6,61\% menggunakan bahasa asing. Sehingga dapat disimpulkan bahwa Suku Dayak lebih dominan mengunakan Bahasa daerah dibanding bahasa Indonesia (BPS, 2017).

Kebiasaan masyarakat Dayak yang selama ini masih menggunakan bahasa daerah menyebabkan terbatasnya kemampuan dalam akses informasi dan inovasi teknologi khususnya bidang pertanian. Hal ini menghambat kemampuan mereka untuk meningkatkan produktifitas usahatani, pendapatan dan kesejahteraannya, Oleh karena itu dibutuhkan pengkajian untuk mengetahui respon dan faktor - faktor apa saja yang mempengaruhi Komunikasi petani terhadap penyuluhan pertanian menggunakan bahasa Indonesia.

\section{METODOLOGI PENELITIAN}

\section{A. Waktu dan Tempat}

Penelitian ini dilaksanakan pada tanggal 1 Juli s/d 1 Agustus 2018 di Desa Entikong, Kecamatan Entikong Kabupaten Sanggau Provinsi Kalimantan Barat.

\section{B. Teknik Pengumpulan Data}

Jenis pengkajian dalam penelitian ini berupa pengkajian deskriptif kuantitatif. Data yang dikumpulkan dalam pelaksanaan pengkajian ini terdiri dari data primer dan data sekunder. Metode pengambilan dan pengumplan data yang digunakan adalah dengan wawancara dan penyebaran kuesioner. Pengumpulan data primer dilakukan dengan melibatkan petani serta keluarga tani, sehingga diharapkan data yang diperoleh betul-betul akurat. Data sekunder dapat diperoleh dari instansi pemerintah yang terkait di Kecamatan Entikong Kabupaten Sanggau.

\section{Populasi dan Sampel}

Populasi dalam pengkajian ini adalah seluruh kelompok tani yang terdapat di desa Entikong. Sementara itu sampel diambil menggunakan metode purposive proportional Random Sampling. Dengan menetapkan beberapa kriteria dalam pemilihan sampel. Rumus yang digunakan dalam menetapkan jumlah sampel adalah Yamane. Presisi yang digunakan dalam pengambilan sampel ini sebanyak 10\%. Adapun rumus Yamane dalam Bungin (2011) yaitu:

$$
\mathrm{n}=\frac{\mathrm{N}}{\mathrm{N} \cdot \mathrm{d}^{2}+1}
$$

Keterangan:

$\mathrm{n}=$ Jumlah sampel

$\mathrm{N}=$ Jumlah populasi

$\mathrm{d}=$ Nilai persen $(10 \%)$

$$
\begin{aligned}
& \mathrm{n}=\frac{411}{411 \cdot(10 \%)^{2}+1} \\
& \mathrm{n}=\frac{411}{411 \cdot(0,1)^{2}+1} \\
& \mathrm{n}=\frac{411}{5,1} \\
& \mathrm{n}=80,43 \longrightarrow \mathrm{n}=80
\end{aligned}
$$

Dari hasil perhitungan yang dilakukan dengan menggunkan rumus Yamane dalam penetapan Sampel penelitian, didapatkan sampel minimum yang harus digunakan yaitu sebanyak 80 responden . Jumlah sampel untuk masing-masing kelompok tani di Entikong akan dibagi menjadi 3 kelompok tani dengan rincian sebagai berikut : 


\begin{tabular}{ccc}
\multicolumn{3}{c}{ Tabel 1. Sampel Pengkajian } \\
\hline No & Kelompok Tani & Jumlah Sampel \\
\hline 1. & Tampu Ijo & 26 \\
2. & Sinar Sekayam & 30 \\
3. & Matahari & 25 \\
& Jumlah & 81 \\
\hline
\end{tabular}

Sumber: BPP Entikong (2018)

\section{Prosedur Pelaksanaan}

Prosedur kegiatan penelitian adalah sebagai berikut:

1. Mengidentifikasi potensi wilayah dan agroekosistem

a. Mengambil dan mengumpulkan data / informasi identifikasi potensi wilayah dengan metode PRA (pelaku utama dan pelaku usaha).

b. Membuat laporan penelitian hasil identifikasi potensi wilayah.

2. Merancang penyuluhan pertanian berdasarkan masalah prioritas yang terjadi di Entikong, dengan merancang metode, media serta materi yang disusun dalam bentuk LPM dan Sinopsis Penyuluhan pertanian

3. Melaksanaan penyuluhan, dilakukan sebanyak 5 kali pertemuann untuk 3 kelompok tani.

\section{E. Analisis Data}

Untuk mengetahui perubahan tingkat pengetahuan petani suku dayak terhadap penyuluhan menggunakan bahasa Indonesia maka digunakan skala likert yang bertujuan untuk mengetahui keefektifan kuisioner. Untuk mengetahui interpretasi digunakan rumus sebagai berikut :

1. Tingkat Pengetahuan

Analisis data tingkat pengetahuan petani menggunakan persamaan:

$\%$ Pengetahuan Petani $=\frac{\text { Jumlah Petani Mengetahui }}{\text { Jumlah Petani Responden }} \times 100 \%$

Pelaksanaan evaluasi penyuluhan pertanian ini ditujukan untuk mengetahui perubahan tingkat pengetahuan petani suku Dayak terhadap penyuluhan menggunakan bahasa Indonesia. Pengukuran kemampuan petani ini terfokus pada satu indikator, yaitu penguasaan petani dalam menyerap komunikasi yang menggunakan bahasa Indonesia sebagai bahasa pengantarnya. Hal ini untuk mengetahui sejauh mana pemahaman petani dalam memahami penyuluhan pertanian menggunakan bahasa Indonesia yang disuluhkan oleh penyuluh kepada kelompok tani sasaran. Kriteria perolehan skor disajikan pada Tabel 1 dan hasil yang diperoleh akan diplot dalam garis kontinum (Gambar 1)

Tabel 2. Kriteria perolehan skor

\begin{tabular}{lll}
\hline 1 & $0 \%-20 \%$ & Tingkat perubahan pengetahuan petani sangat rendah \\
2 & $21 \%-40 \%$ & Tingkat perubahan pengetahuan petani rendah \\
3 & $41 \%-60 \%$ & Tingkat perubahan pengetahuan petani sedang \\
4 & $61 \%-80 \%$ & Tingkat perubahan pengetahuan petani tinggi \\
5 & $81 \%-100 \%$ & Tingkat perubahan pengetahuan petani sangat tinggi \\
\hline
\end{tabular}

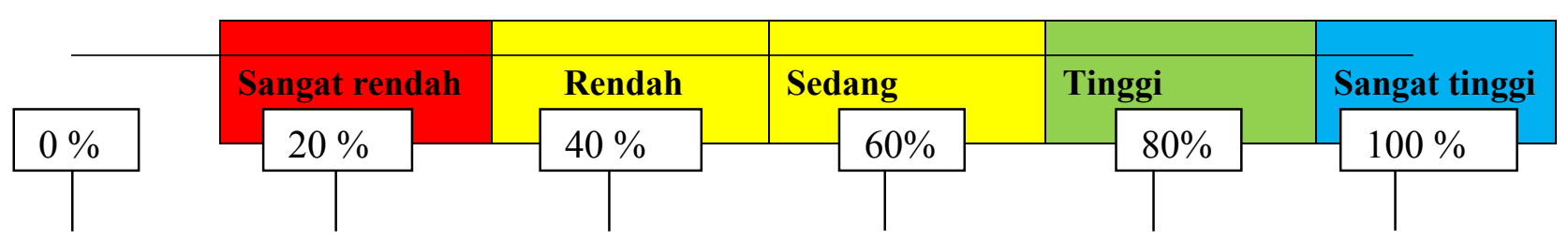

Gambar 1. Garis kantinum perubahan sikap petani 


\section{HASIL DAN PEMBAHASAN}

\section{A. Karakteristik Internal Petani}

1. Umur

Umur merupakan salah satu faktor yang berperan sangat penting didalam proses penyerapan informasi penyuluhan pertanian. Berdasarkan hasil wawancara yang dilakukan terhadap 20 petani responden tingkat umur, didapatkan hasil yang disajikan pada Tabel 3.

Tabel 3. Rekapitulasi Tingkat Umur Petani Responden di Desa Entikong.

\begin{tabular}{ccc}
\hline Umur & Jumlah (orang) & Persentase (\%) \\
\hline $20-30$ & 20 & 25 \\
$31-40$ & 12 & 15 \\
$41-50$ & 16 & 20 \\
$51-60$ & 24 & 30 \\
$>60$ & 8 & 10 \\
Jumlah & 80 & 100 \\
\hline
\end{tabular}

Dari Tabel 3 menunjukan bahwa sebagian responden berada pada tingkatan umur 20 - 50 tahun adalah sebanyak 48 orang (60\%) yang artinya lebih dari setengah dari responden termasuk dalam kategori umur produktif dan jika dihubungkan dengan adopsi maka responden termasuk petani yang cepat dalam menerapkan suatu inovasi atau perubahan tertentu. Termasuk daya serap terhadap penyuluhan pertanian menggunakan bahasa Indonesia.

Seperti diungkapkan oleh Soekartawi (1988), bahwa makin muda umur penduduk biasanya mempunyai rasa ingin tahu yang tinggi dan berusaha untuk lebih cepat melakukannya walaupun belum berpengalaman. Semakin tua (diatas 50 tahun) biasanya semakin lamban menerapkan inovasi dan cenderung hanya melaksanakan kegiatan yang sudah biasa dilakukan masyarakat setempat (Lionberger, 1960; Mardikanto, T., 2009).

\section{Tingkat pendidikan}

Tingginya anak putus sekolah dan rendahnya kualitas sumberdaya manusia merupakan permasalahan utama di bidang pendidikan. Sumberdaya manusia yang ada pada pengembangan sektor pertanian dan sektor lainnya karena rendahnya tingkat pendidikan penduduk. Adapun jumlah responden yang mengikuti pendidikan mulai dari sekolah dasar sampai perguruan tinggi disajikan pada Tabel 4.

Tabel 4. Rekapitulasi Tingkat Pendidikan Formal Petani Responden Desa Entikong.

\begin{tabular}{ccc}
\hline Pendidikan Formal & Jumlah (orang) & Persentase (\%) \\
\hline Tidak sekolah & - & 0 \\
SD & 24 & 30 \\
SLTP & 16 & 20 \\
SLTA & 36 & 45 \\
Perguruan Tinggi & 4 & 5 \\
Jumlah & 80 & 100 \\
\hline
\end{tabular}

Tabel 4 menunjukan bahwa tingkat pendidikan petani responden dominannya adalah tamat SMA berjumlah 36 orang (45\%) dan SMP berjumlah 16 orang (20\%), tamatan SD sebanyak 24 orang (30\%) dan 4 orang yang mengenyam pendidikan di perguruan tinggi. Hal ini menunjukkan masih rendahnya tingkat pendidikan petani di Desa Entikong. Tingkat pendidikan responden akan mempengaruhi penerimaan mereka terhadap hal-hal baru. terutama dalam daya tangkap petani dalam penerimaan informasi menggunakan bahasa Indonesia. Manurut Suhardino; Mardikanto (1993) bahwa kemampuan petani dalam menerima hal - hal baru banyak bergantung pada tingkat pendidikan yang mereka miliki. Tingkat pendidikan tamatan SLTP, SLTA dan PT ini, diharapkan petani dapat semakin terbuka terhadap segala teknologi baru yang ada disekitar. 
3. Jumlah Menurut Jenis Kelamin.

Jenis kelamin menunjukkan kemampuan fisik dalam berusaha tani. Selain itu, jenis kelamin juga berpengaruh terhadap kemampuan memimpin dan mengambil keputusan dalam berbagai kegiatan termasuk dalam kegiatan usahatani.

Tabel 5. Rekapitulasi Jumlah Petani Responden Berdasarkan Jenis Kelamin di Desa Entikong.

\begin{tabular}{cccc}
\hline No & Jenis kelamin & Jumlah orang & Parsentase \% \\
\hline 1 & Laki-laki & 80 & 100 \\
2 & Perempuan & - & - \\
& Jumlah & 80 & 100 \\
\hline
\end{tabular}

Berdasarkan Tabel 5, dapat dilihat bahwa responden dalam evaluasi ini adalah laki - laki semua. Hal ini menunjukkan bahwa kaum laki - laki lebih banyak berperan dalam melakukan usaha tani padi dan untuk yang perempuan hanya menjadi tenaga bantuan untuk laki - laki.

\section{Luas Lahan yang Diusahakan.}

Luas lahan garapan petani responden dapat dipengaruhi oleh produktivitas petani itu sendiri. Semakin luas lahan garapan semakin banyak produksi luas lahan akan mempengaruhi produksi disajikan pada Tabel 6.

Tabel 6. Rekapitulasi Luas Garapan Petani Responden di Desa Entikong

\begin{tabular}{ccc}
\hline Luas garapan $(\mathrm{Ha})$ & Jumlah (orang) & Persentase (\%) \\
\hline 0 & - & \\
$0,25-0,50$ & 40 & 50 \\
$0,51-1$ & 40 & 50 \\
Jumlah & 80 & 100 \\
\hline
\end{tabular}

Berdasarkan Tabel 6, dapat dilihat bahwa luas lahan petani responden rata-rata mempunyai luas lahan $0,25-1$ ha sebanyak 80 orang $(100 \%)$ yang berarti dengan luas garapan lahan petani responden tersebut, dapat berpengaruh terhadap adopsi petani dalam penerimaanya terhadap informasi dalam penyuluhan pertanian menggunakan bahasa Indonesia. Mardikanto (2009), mengemukakan semakin luas usahatani biasanya semakin cepat meningkatkan penghasilannya, karena memiliki kemampuan ekonomi yang lebih baik.

\section{B. Penerapan Teknologi}

\section{Pengetahuan}

Pada pelaksanaan evaluasi penyuluhan pertanian mengukur tingkat perubahan pengetahuan petani setelah mendapatkan penyuluhan pertanian menggunakan bahasa Indonesia dengan judul materi penyuluhan pengenalan dan cara mengendalikan penyakit kresek di Desa Entikong menggunakan instrumen berupa kuisioner atau pertanyaan pilihan berganda. Hasil analisa tingkat perubahan pengetahuan petani sebelum dan sesudah diberikan penyuluhan pertanian menggunakan bahasa Indonesia. Data pretest (sebelum penyuluhan) diperoleh tingkat pengetahuan petani penyuluhan pertanian menggunakan bahasa Indonesia senilai $41,75 \%$ (Skala C) atau sedang sedangkan pada posttest (setelah penyuluhan) diperoleh tingkat pengetahuan petani penyuluhan pertanian menggunakan bahasa Indonesia senilai 63,32\% (Skala B) atau Tinggi. Hal ini menunjukan bahwa pengaruh dari penyuluhan meningkatkan perubahan pengetahuan petani setelah medapatkan penyuluhan bahasa Indonesia sebesar 21, 575\%. Dilihat berdasarkan garis kuantur, maka didapat hasil seperti Gambar 2.

Hasil analisa tingkat perubahan pengetahuan petani dalam kegiatan penyuluhan pertanian menggunakan bahasa Indonesia menunjukan bahwa pengaruhnya terhadap perubahan pengetahuan petani dalam kategori rendah yakni hanya sekitar $21 \%$ ini dikarenakan banyak faktor. Salah satu faktor yang mempengaruhi yakni pendidikan dan umur. Faktor - faktor tersebut sangat berpengaruh terhadap keberhasilan penyuluhan pertanian, sebagaimana yang dikatakan oleh Mardikanto (2009) bahwa kapasitas belajar seseorang akan dipengaruhi oleh latar belakang pendidikan seseorang dan cenderung melaksanakan kegiatan-kegiatan yang sudah biasa diterapkan oleh masyarakat setempat. 


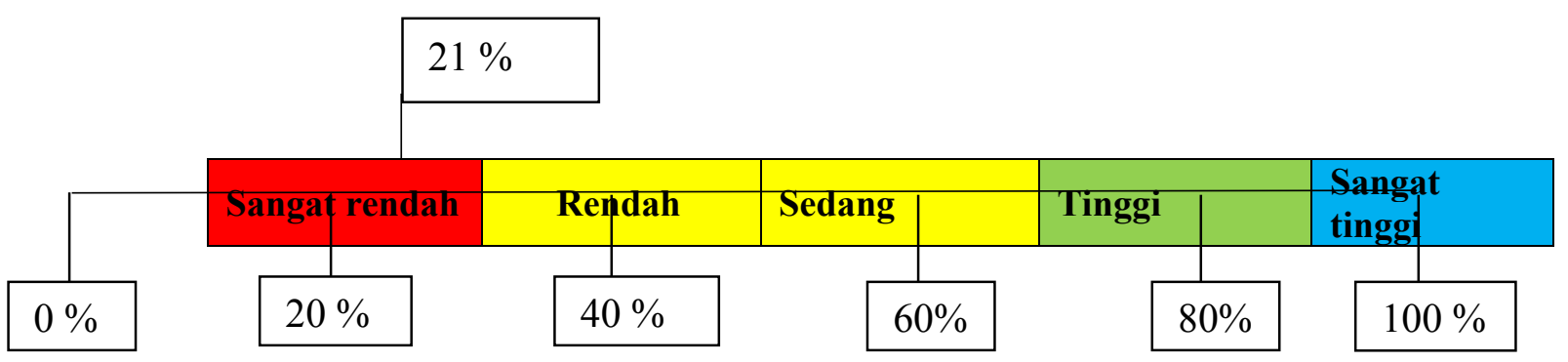

Gambar 2. Garis kantinum perubahan pengetahuan petani

Jika dihubungkan dengan daya ingat tentang teknologi, maka petani yang berada pada pendidikan yang tinggi yaitu termasuk kategori petani yang terbiasa berkomunikasi menggunakan bahasa Indonesia, berbeda dengan petani suku dayak lainnya yang didominasi oleh petani dengan latar pendidikan SD dan SMP, mereka cenderung menggunakan bahasa dayak dalam berkomunikasi seharihari, sehingga ada beberapa orang dari petani suku dayak yang bahkan tidak mengerti dengan bahasa Indonesia .

Penguasaan Bahasa nasional sangat berpengaruh terhadap pola pikir dan pengembangan kreatifitas masyarakat. Hal ini disebabkan banyaknya informasi penting yang menggunakan bahasa Indonesia sebagai bahasa pengantarnya, seperti di berbagai media cetak dan elektronik, literatur dari buku, modul dan lain sebagainya. Ini seharusnya menjadi perhatian kita bersama bahwa sebenarnya masih banyak masyarakat perbatasan yang belum mengerti bahasa nasional mereka sendiri. Sehingga dibutuhkan penyuluhan dan propaganda dalam menggaungkan kembali bahasa Indonesia diberbagai wilayah di Indonesia terutama di daerah perbatasan.

\section{KESIMPULAN}

Berdasarkan penelitian yang telah dilakukan, didapatkan hasil tingkat respon petani suku Dayak terhadap penyuluhan pertanian didapatkan perbuahan pengetahuan sebesar $21,57 \%$, dengan presentase sebelum penyuluhan (prittest) sebesar $41,75 \%$ dan persentase sesudah penyuluhan pertanian ( posttest) sebesar 63,32\%. Tingkat respon petani Suku Dayak terhadap penyuluhan pertanian dengan menggunakan bahasa Indonesia berada dalam kategori rendah. Adapun faktor yang paling mempengaruhi daya serap petani suku dayak terhadap penyuluhan pertanian menggunakan bahasa Indonesia adalah faktor latar belakang pendidikan dan umur petani.

\section{UCAPAN TERIMAKASIH}

Dalam penelitian dan penyusunan artikel ilmiah ini, saya memperoleh bantuan dari berbagai pihak, baik secara langsung maupun tidak langsung. Untuk itu saya mengucapkan terimakasihyang sebesar besarnya kepada pihak - pihak yang telah membantu terlaksananya penelitian ini

\section{DAFTAR PUSTAKA}

Badan Pusat Statistik. 2016. Indeks Pembangunan Manusia Tahun 2016. www.bps.go.id Badan Pusat Statistik. 2017. Badan Pusat Statistik Tabel Dinamis. https://bps.go.id/site/result Bungin, Burhan. 2011. Metodologi Penelitian Kuantitatif: Komunikasi, Ekonomi, dan Kebijakaan Publik serta Ilmu - Ilmu Sosial lainnya. Jakarta: Kencana

De Vito, Joseph, A. 1997. The Interpersonal Communication Book: Professional Book. Jakarta Lionberger, Harbert F. 1960. Adoption Of New Ideas and Practices. The Iowa State University Press. U.S.A. 164 hal.

Mardikanto, Totok. 1993. Penyuluhan Pembangunan Pertanian. Sebelas Maret University Press. Surakarta

Mardikanto, T. 2009. Sistem Penyuluhan Pertanian. UNS Press. Surakarta.

Mardikanto dan Soebiato. 2013. Pemberdayaan Masyarakat dalam Prespektif Kebijakan Publik. Bandung: Alfabeta. 
Jurnal Teknologi Pertanian Andalas Vol. 23, No.1, Maret 2019, ISSN 1410-1920, EISSN 2579-4019

Rifqi Pascavery Dwipani, Maya Khairunisa, Ameilia Zuliyanti Siregar, dan Nurliana Harahap

Nasution, Z. 1990. Prinsip Prinsip Komunikasi Untuk Penyuluhan. Lembaga Penerbit Fakultas Ekonomi Universitas Indonesia. Jakarta.

Nurhidayati, dkk. 2008. E-Book Pertanian Organik. Malang. Program Studi Agroteknologi, Jurusan Budidaya Pertanian, Fakultas Pertanian Universitas Islam Malang. 196 hal.

Pujianto. 2010. Pemanfaatan Kotoran Ternak Sapi Sebagai Sumber Energi Alternatif Ramah Lingkungan Beserta Aspek Sosio Kulturalnya. Inotek (13). Vol.2. 150-160

Suwandi, A. 2006. Diktat: Implementasi Participatory Rural Appraisal(PRA). Sekolah Tinggi Penyuluhan Pertanian Bogor: Bogor. 